\title{
Erratum to: A Process Integrated Engineering Knowledge Acquisition and Management Model for a Project based Manufacturing
}

\author{
Jinteck Han, Soo-Hong Lee , and Jae Kwan Kim
}

Published online: 05 February 2017

(c) 2017 by KSPE and Springer

Int. J. Precis. Eng. Manuf., Vol. 18, No. 2, pp. 175-185, 2017

DOI: $10.1007 / \mathbf{s} 12541-017-0023-6$

The ACKOWLEDGEMENT of the above the article has been corrected as follows:

This research was supported by the LNG Plant R\&D Center which belongs to the Plant Technology Advancement Program funded by the Ministry of Land, Infrastructure and Transport of the Korea government (16IFIP-B091004-03) and the Future Fundamental Research Program of the Korea Institute of Science and Technology (2E26880).

The online version of the original can be found under doi:10.1007/s12541-017-0023-6

\#Corresponding Author: Soo-Hong Lee

Department of Mechanical Engineering, Yonsei University, Seoul, South Korea

E-mail: shlee@yonsei.ac.kr 